\title{
Prevalence and characteristics of driving difficulties in Operation Iraqi Freedom/Operation Enduring Freedom combat returnees
}

\author{
Henry L. Lew, MD, PhD; ${ }^{1-2 *}$ Malissa Kraft, PsyD; ${ }^{3}$ Terri K. Pogoda, PhD; ${ }^{3-5}$ Melissa M. Amick, PhD; ${ }^{3,6}$ Patricia \\ Woods, RN, MSN; ${ }^{3}$ David X. Cifu, MD $^{7}$ \\ ${ }^{1}$ Defense and Veterans Brain Injury Center (DVBIC), Richmond, VA; ${ }^{2}$ University of Manoa, Honolulu, HI; ${ }^{3}$ Polytrauma \\ and Traumatic Brain Injury Research Center, Department of Veterans Affairs (VA) Boston Healthcare System, Boston, \\ $M A ;{ }^{4}$ Center for Organization, Leadership, and Management Research, VA Boston Healthcare System, Boston, MA; \\ ${ }^{5}$ Department of Health Policy and Management, Boston University School of Public Health, Boston, MA; ${ }^{6}$ DVBIC, \\ Boston, MA; ${ }^{7}$ Physical Medicine and Rehabilitation Service, Hunter Holmes McGuire VA Medical Center, Richmond, VA
}

\begin{abstract}
We studied the prevalence and characteristics of selfreported driving difficulties and examined their association with traumatic brain injury (TBI) and/or posttraumatic stress disorder (PTSD) in Operation Iraqi Freedom/Operation Enduring Freedom (OIF/OEF) veterans who were seen at a Department of Veterans Affairs outpatient polytrauma clinic. In this study, we used a brief driving questionnaire and chart reviews to assess the prevalence and characteristics of driving difficulties in the following four groups of patients: TBI only, PTSD only, TBI + PTSD, and Neither (neither TBI nor PTSD). Compared with before deployment, $93 \%$ of OIF/OEF veterans seen in the polytrauma clinic reported more difficulties with driving in at least one domai n, with the most common areas of $d$ ifficulty being (1) problems with anger or impatience (82\%), (2) general driving difficulties (65\%), and (3) experiences with near misses (57\%). Patients with PTSD (with or without TBI) reported the most significant driving impairments, whereas respondents with a history of only TBI endorsed driving difficulties similar to veterans without either diagnosis. Qualitative an alysis of veterans' co mments also revealed similar patterns. Self-reported driving problems were common among OIF/OEF returnees. Respondents who had a diagnosis of PTSD (with or without TBI) reported the most severe driving difficulties since returning from deployment. The association between PTSD and driving problems warrants further investigation.
\end{abstract}

Key words: automobiles, combat, concussion, deployment, driving, OIF/OEF, posttraumatic stress disorder, road rage, traumatic brain injury, veterans.

\section{INTRODUCTION}

Injury due to motor vehicle crashes is one of the leading causes of prev entable morbidity and mortality across all branches of the military [1]. Furthermore, motor vehicle crashes are the leading cause of death in veterans in the early years after returning from deployment [2]. This find ing has been observed in both Gulf war and Vietnam veterans [3-6]. In 1991, deployed Gulf war veterans had an annual rate of 23.6 fatalities per 100,000 persons - a much higher rate than nondeployed veterans (15.9 per 100,000 persons) [4] or the general U.S. population around that time (16.3 per 100,000 persons) [7]. A recent study has shown that during the first 5 years following return from deplo yment, Operation Iraqi Freedom/Operation Enduring Freedom (OIF/OEF)

\footnotetext{
Abbreviations: $\mathrm{ANOVA}=$ analysis of variance, $\mathrm{CI}=$ confidence interval, $\mathrm{mTBI}=$ mild traumatic brain injury, $\mathrm{OIF} / \mathrm{OEF}=$ Operation Iraqi Fre edom/Operation Enduring Freedom, OR = odds ratio, $\mathrm{PCS}=$ postconcussion syndrome, $\mathrm{PNS}=$ Polytrauma Network Site, PTSD = posttraumatic stress disorder, $\mathrm{SD}=$ standard deviation, $\mathrm{TBI}=$ traumatic brain injury, $\mathrm{VA}=$ Department of Veterans Affairs.

* Address all correspondence to Henry L. Lew, MD, PhD; University of Hawaii at Manoa, 1410 Lower Campus Road, Honolulu, HI 96822; 808-956-5484. Email: hlew@dvbic.org DOI:10.1682/JRRD.2010.08.0140
} 
veterans have a 75 percent greater risk of death from amotor vehicle accident than the general population [2]. Given these findings, the Department of Veterans Affairs (VA), Department of Transportation, and Department of Defense recently developed an initiati ve to reduce motor vehicle accidents among this cohort [2].

Several possible factors may co ntribute to increased driving problems in military personnel relative to the general population [8].Veterans may engage in mo re risky driving behaviors; as o ne study observed that approximately 19 percent of U.K. armed forces personnel (active and reserve) reported speed ing and/or not wearing seatbelts when driving in civilia $\mathrm{n}$ settings [9]. One explanation for these driving issues is that demographic variables known to be risk factors for motor vehicle fatalities (i.e., being young, male, unmarried, and having a high school education or less) are characteristic of military personnel [10]. Additionally, deployment seems to co nvey unique and additive risk for driving difficulties. Lincoln et al. found that Gulf war era veterans who had been deployed had a sign ificantly higher annual rate of mo tor vehicle fatalities (between 1991 and 1995) than those who served during the same period but were not deployed [4]. It has been proposed that exposure to and su rviving traumatic events, such as those experienced during war, contribute to a personal sense of invulnerability, which may result in increased risk-taking behavior [11].

Other factors specific to OIF/OEF veterans may place them at even greater risk of postdeployment driving difficulties than veterans of previous wars. Before deploy ment, OIF/OEF servicemembers undergo "battlemind" training [12]. One component of this training involves learning aggressive or combat driving practices that are used during deployment. Examples of such skills include driving quickly and erratically, making rapid and unpredictable lane changes, straddling the middle line, and attempting to keep other vehicles at a distance to avoid explosives and ambushes [13]. These skills are contrary to the driving rules and behaviors that are required to drive safely in a civilian environment, and for some veterans, "unlearning" these maneuvers when they return home may be difficult [13].

The most common OIF/OEF combat-related conditions, posttraumatic stress disorder (PTSD) and traumatic brain injury (TBI), likely place these veterans at an additional risk of postdeployment driving dif ficulties [14]. The prevalence of PTSD among Vietnam and Gulf war veterans has been e stimated to be 19 and 10 percent, respectively [15-16], and may be even more common among OIF/OEF veterans. Prevalence estimates of PTSD for this cohort have ranged between 11 and 18 percent [17-20], although some estimates have been upwards of 30 percent [21]. Given that the war is ongoing and many soldiers have multiple deployments [21-22], a factor shown to increase risk of de veloping PTSD [23], PTSD prevalence rates among OIF/OEF servicemembers could grow even higher.

PTSD could be as sociated with unsa fe driving practices for multiple reasons. First, PTSD negatively affects cognitive functioning [24], especially in the domains of attention [25], executive functioning [26], and processing speed [27], all of which are essential to blocking out distractions, reacting to challenging situations, and using good judgment while driving. Second, a characteristic of the disorder is irritability an d outbursts of anger, which could lead to agg ressive driving and impulsive or risky driving behaviors [28]. Finally, increased startle response (e.g., becoming excessively alarmed at the sound of a backfiring car, screeching tires, etc.), another common feature of PTSD, also might create dangerous situations while driving. To date, no research that we are aware of has examined this issue.

In addition to increased rates of PTSD, TBI is believed to account for a greater proportion of injuries in OIF/OEF than in previous wars [29-30]. An estimated 11 to 20 percent of soldiers have sustained a TBI during their deployment [17,31], with nearly 80 percent of those injuries being mild in nature [32]. While most symptoms resulting from mild TBI (mTBI) typically resolve within a few weeks or months of the injury, a small percentage of people continue to experience symptoms for several months or even years. These symptoms, collectively known as postconcussion syndrome (PCS), typically include cognitive difficulties such as memory and concentration impairment, somatic complaints (i.e., he adache, dizziness), and emotional disturbance including irritability, depression, and anxiety [32], all of which might interfere with driving. Research suggests a strong association exists between PCS and PTSD [33-34], and many potential symptoms that could affect driving are shared between disorders [8].

Before strategies to prevent and correct driving issues can be put into place, a better understanding is needed of the frequency and types of driving difficulties being experienced by OIF/OEF veterans and these veterans' characteristics. The following study of OIF/OEF veterans was an exploratory analysis that aimed to (1) document 
and describe driving difficulties in a cohort of vet erans seen within a VA Polytrauma Network Site (PNS) outpa tient clinic and (2) determine how TBI and P TSD, two common clinical diagnoses among this cohort, are associated with self-reported driving difficulties.

\section{METHODS}

\section{Sample and Procedure}

Participants for this survey study were recruited from a VA PNS from September 2009 to November 2009. All veterans seen in the pol ytrauma outpatient clinic between October 2006 and May $2009(n=450)$ were identified as potential participants. Each veteran was mailed a letter that contained a description of the study, a brief questionnaire about driving difficulties, and a "participation declined" reply card. If no r eply was received within 3 weeks, research staff attempted to ca ll the veteran to administer the survey questions over the telephone. If con tact could not be established with a veteran after three attempts over a 2-week time p eriod, the poten tial subject was excluded from possible participation. Veterans who had not driven since returning from their deployment an $\mathrm{d}$ those who served in a war other than OIF/OEF were also excluded (Figure 1).

\section{Driving Questionnaire}

The brief driving questionnaire is a seven-item measure that asks participants to i ndicate how their po stdeployment

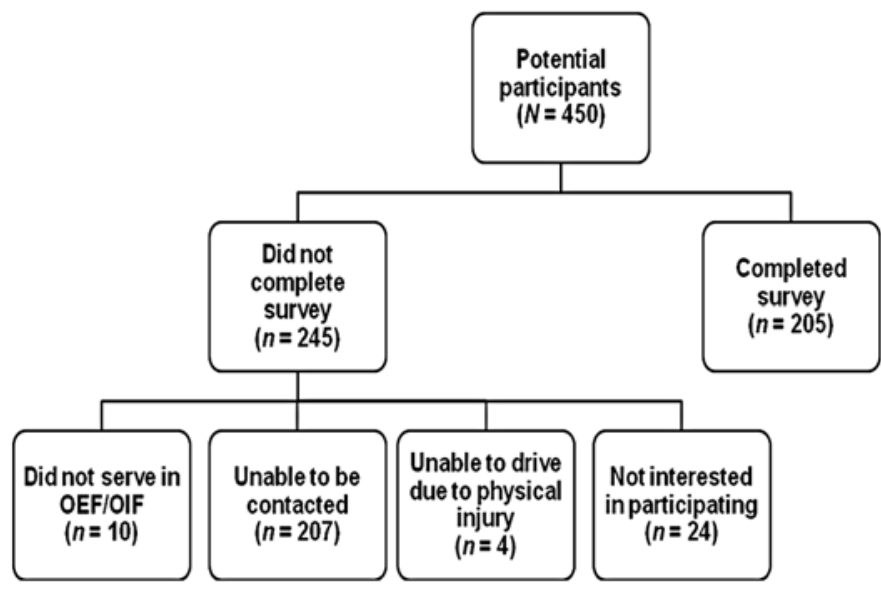

Figure 1.

Population and study respondents to survey of postdeployment driving difficulties. OEF/OIF = Operatio n Enduring Freedom/Operation Iraqi Freedom. driving-related behavior compares with their predeployment driving behavior (see Appendix, available online only). The questions address (1) general driving difficulties, (2) receipt of a warning by the police for traffic violations, (3) receipt of a traffic citation (ticket or fine), (4) occurrence of driv ing accidents, (5) ins tances of nea $r$ misses while driving, (6) problems with anger or impatience while driving, and (7) instances of becoming lost or disorie nted while driving. The questionnaire asks respondents to report problems in terms of less than, the same, or more than before deployment. For the purposes of analysis, responses were reclassified into "more than before deployment" or "not more than before deployment."

\section{Demographic and Military Information}

Participants were asked to answer several demographic questions regarding race/ethnicity, marital status, years of education, and branch of military. They were also asked to indicate how many tou rs of duty they had served in OIF/ $\mathrm{OEF}$, which year they returned from their most recent tour of duty, and how frequently they drove military vehicles during their tour of duty (frequently, occasionally, or rarely/never).

\section{Respondent Comments}

Veterans surveyed by telephone also had the opportunity to provide further comments on the driving questionnaire. Any information that was shared by the respondent was recorded by the research team member administering the questionnaire.

\section{Chart Review}

A neuropsychologist (MMA or MK) reviewed the electronic medical records of all veterans who completed the driving questionnaire. The purpose of the chart review was to document a history of TBI or PTSD. Based on the presence or absence of these diagnoses, participants were classified into one of four clinical groups: TBI only, PTSD only, TBI + PTSD, or Neither (no TBI or PTSD). * Historically, mTBI is the most common TBI diagnosis among patients seen at a VA polytrauma outpatient clinic.

\footnotetext{
*Mental health conditions that were documented in the patient elec tronic medical record were examined for the Neither group: 43.5 percent had no mental health condition, 21.7 percent had an adjustment disorder, 13.0 percent depressio n, 13.0 percent anxiety, 4.3 percent mood disorder, and 4.3 percent a combination of any of the above.
} 


\section{TBI Diagnosis}

Before their recruitment to the study, all study participants had completed a co mprehensive TBI evaluation as part of their pol ytrauma clinic vi sit. The comprehensive TBI evaluation involved a medical examination by a physiatrist, and a standardized VA protocol was used to assess the veteran's injury-related history and deployment-related experiences associated with injuries, exposure to blast, and immediate postblast/injury experiences. Participants were classified as having a histo ry of TBI, as defined by the American Congress of Rehabilitation Medicine [35], if they reported having experienced at least one of the following: alteration of consciousness, posttraumatic amnesia, or loss of consciousness. For this study, the compreh ensive TBI evaluation note entered into the patient's electronic medical record was the primary source used to document history of TBI. For each study participant with a history of TBI, the severity (mild, moderate, or severe) was also documented according to the currently accepted VA and Department of Defense criteria based on the durations of alteration of consciousness, posttraumatic amnesia, or loss of consciousness [35-36].

\section{PTSD Diagnosis}

Each participant's electronic medica 1 record was reviewed by a neuropsychologist to determine whether the participant had a previous diagnosis of PTSD. Participants were classified as having a history of PTSD if a VA mental health provider (i.e., psyc hologist or psychiatrist) had assessed and subsequently diagnosed the participant with PTSD.

\section{Data Analysis}

Group characteristics were examined with the use of chi-square for categorical variables (e.g., sex, marital status, education level) and analysis of variance (ANOVA) for continuous variables (e.g., age, time back since most recent deployment). When appropriate, the Tukey Honestly Significant Difference test was used for AN OVA post hoc comparisons. Logistic regression was used to test for the effects of PTSD (yes, no), TBI (yes, no), and any significant covariates on the seven driving survey questions with dichotomous outcomes (problems with driving-related issues: more than before deployment, not more than before deployment). Due to the exploratory nature of this analysis, the alpha significance level was set at 0.05 .

\section{Qualitative Analysis of Driving Questionnaire}

In addition to responding to the driving questionnaire, 60 telephone respondents also offered comments regarding driving-related changes they had experienced since returning from deployment. These comments ranged from sharing stories about specific experiences to thoughts about why they believed such changes had occurred. Some comments described problems that were initially experienced but had since resolved, while others described ongoing driving difficulties. One research team member de-identified comments offered by driving questionnaire telephone respondents, and three other research team members reviewed all de-identified questionnaire responses independently and developed a coding scheme for categorizing them. The team members the $\mathrm{n}$ met to discus $\mathrm{s}$ common themes and reached consensus on a final co ding list of 10 categories. Responses were also coded according to the persistence or resolved state of the complaint. Each reviewer then recoded all the responses based on this list and met again for a final coding $\mathrm{c}$ omparison. All coders reached c onsensus for each response.

\section{RESULTS}

\section{Participant Characteristics}

A total of 205 (45.6\%) OIF/OEF veterans completed the driving questionnaire (telephone, $n=153$; mail, $n=52$ ). Rates of PTSD and TBI were not significantly associated with sex, race/ethnicity, education level, marital status, branch of military, frequency of driving while deployed (for all $\left.\chi^{2}, p>0.05\right)$, ag e (mean \pm standard deviation $[\mathrm{SD}]=$ $33.5 \pm 10.0$ years; all $F(1,203<1.15, p>0.25)$, or number of tours (mean $\pm \mathrm{SD}=1.48 \pm 0.73$; all $F(1,203)<1.50, p>$ $0.20)$. Response rates by mail or survey also did not differ as a function of clinical group, all $\chi^{2}(1)<1.00, p>0.05$. Participants reported that they had returned from their most recent deployment between 2003 and 2009. Each response was converted to a numeric value based on the midpoint of the year that was indicated (e.g., $2009=0.5$ years; $2008=$ 1.5 years). On average, respondents had been back for $3.73 \pm 1.39$ years, but groups varied in their time since return from deployment, $F(3,201)=4.55, p=0.004$. Participants with PTSD (mean \pm SD $=3.85 \pm 1.40$ ) had been back significantly longer than participants without PTSD (mean $\pm \mathrm{SD}=3.45 \pm 1.33$ ), $F(1,201)=6.04, p<$ 0.02 . There was no significant dif ference in time since return for patients with TBI, $F(1,201)=2.56, p>0.05$, but 
there was a marginally significant PTSD $\times$ TBI interaction, $F(1,201)=3.47, p<0.07$. Among patients with PTSD, those without TBI (PTSD only group) had been back from deployment significantly longer (mean $\pm \mathrm{SD}=4.35 \pm 1.42$ ) than those without TBI (Neither group, mean $\pm \mathrm{SD}=3.60 \pm$ $1.33), t(146)=3.16, p=0.002$. Additional participant characteristics are summarized in Table 1.

\section{Driving Questionnaire}

Approximately 93 percent of respondents reported having more difficulties with driving in at least one domain compared with before deployment. Of the seven domains addressed in the questionnaire, the three most frequently endorsed driving-related problem areas were (1) problems with anger or impatience (82\%), (2) general driving difficulties (65\%), and (3) experiences with near misses (57\%). While the speci fic prevalence rates differed, this pat tern held true for all four clinical groups (Figure 2).

\section{Relationship of TBI and PTSD with Driving Problems}

Because there was a significant group difference in time back since deployment, this variable was included as a covariate for the logistic regression analyses. Responses to questions related to postdepl oyment general driving issues, traffic warnings, tickets, accidents, and near misses did not vary as a function of a TBI or PTSD diagnosis. There was a significant model related to postdeployment driving-related anger or impatience, $\chi^{2}(4)=10.59, p<0.04$. Participants who had a diagnosis of P TSD were more than three times more likely to report increased anger or impatience while driving relative to participants without a $\mathrm{P}$ TSD diagnosis (odds ratio $[\mathrm{OR}]=3.65,95 \%$ confidence interval $[\mathrm{CI}]=$ $1.08-12.31, p<0.04$.) Clinical groups also differed in selfreported problems with becoming lost or disoriented while driving, $\chi^{2}(4)=11.31, p<0.03$. Part icipants with PTSD were significantly more likely to report becoming lost or disoriented while driving than participants without $\mathrm{P}$ TSD $(\mathrm{OR}=6.06,95 \% \mathrm{CI}=1.88-19.46, p<0.003)$. There was also a marginal effect of TBI $(\mathrm{OR}=2.84,95 \% \mathrm{CI}=0.86-$ 9.44, $p<0.09$ ). However, these main effects were moderated by a significant PTSD $\times$ TBI interaction $(\mathrm{OR}=0.22$, $95 \% \mathrm{CI}=0.05-0.89, p<0.04)$. Follow-up analyses found that among participants without TBI, a significantly higher percentage of participants with PTSD only $(62.5 \%)$ reported having more postdeployment driving problems with disorientation or getting lost than the percentage of participants in the Neither group $(21.7 \%), \chi^{2}(1)=10.34, p=0.001$. No significant effect was observ ed in participants with TBI.
Table 1.

Respondent demographics and characteristics. $N=205$

\begin{tabular}{lc}
\multicolumn{1}{c}{ Participant Characteristic } & Frequency \\
\hline (\%)
\end{tabular}

Whether participants with TBI had a diagnosis of P TSD $(51.0 \%)$ or not $(44.1 \%)$, participants were statistically equally likely to report problems with disorientation or getting lost, $\chi^{2}(1)=0.48, p=0.49$.

\section{Respondent Comments}

The categorization of telephone participant responses may be seen in Table 2. Some veterans offered multipart responses that fell into more than one category. In these 


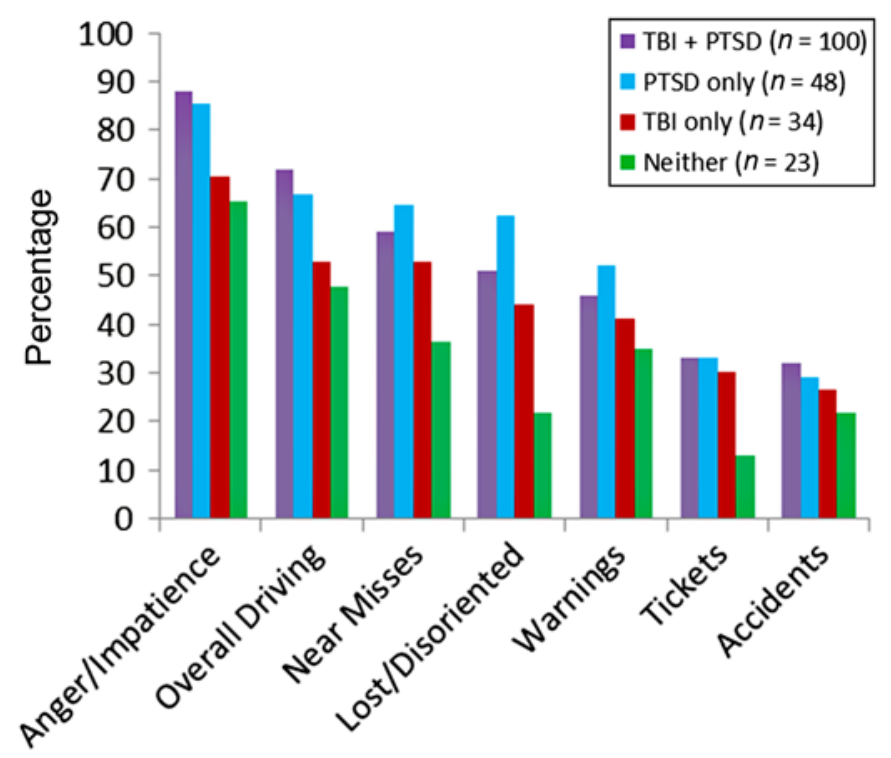

Figure 2.

Prevalence of veterans' self-reported postdeployment driving difficulties by clinical group: posttraumatic stress disorder (PTSD) only, traumatic brain injury (TBI) only, TBI and PTSD (TBI + PTSD), and $n$ either condition (Neither).

cases, the comments were co ded for multiple categories; however, responses for a single veteran were only counted once per category. Comments were offered by 60 participants, and this resulted in a total of 99 responses that were reported and coded. Review of the responses revealed that four was the maximum number of categories coded from a single participant's multipart comment. Table 3 represents the breakdown of the persisting versus imp roved/ resolved classification for each of the four clinical groups.

\section{Frequently Reported Driving Problems}

Consistent with the pattern of response to the driving questionnaire, the most common theme that emerged from the qualitative data was a self-perceived increase in postdeployment anger, aggression, or impatience while driving. Approximately one-fifth of the responses indicated that the veterans drove (and continue to drive) more aggressively. Specifically, driving behaviors such as speeding and tailgating were described, in addition to general aggressive driving maneuvers. Several veterans noted that they had sought treatment for their aggression.

The second most common driving-related problem that veterans commented on was lapses in attention. Many described this phenomenon as "zoning out" while driving. The consequences of this issue ranged from relatively benign experiences, such as frustration over being unable to stay focused on where they were going, getting lo st, and missing a turn or exit, to more concerning problems such as getting distracted and having more near misses or getting into accidents. Some veterans stated that when they zoned out, they were actually thinking about deployment-related experiences. Approximately 15 percent of the co mments fell into this category, and among these, only on e participant indicated that the problem had resolved.

Respondents also described difficulty in adjusting from driving in a combat zone to driving in a civilian environment. The comments that fell under this category we re varied but generally indicated that many participants had (and continue to have) difficulty adjusting to driving in an envi ronment that is relatively free of danger or threat. For example, several veterans reported that after returning home they continued to use battlemind driving skills that they had been taught to u se to avoid being attacked during deployment (e.g., ignoring stop signs, not yielding to pedestrians). They also noted that they became anxious in driving situations that were not anxiety-provoking before deployment (e.g., driving over bridges, through tunnels, or in h eavy traffic). Veterans stated that they also tended to confuse objects on the road (e.g., pothole s, trash) for im provised explosive devices and tended to overreact to such stimuli by driving in the middle of the road or quickly swerving into other lanes to avoid contact with the se objects. Some veterans also reported increased startle response since returning from deployment, such as experiencing intense anxiety or taking cover (while still dri ving) when hearing screeching tires. Although many legitimate potential driving threats existed in Iraq or Afghanistan, many veterans continued to perceive threats in similar driving situa tions even though they were no longer in a dangerous or threatening environment. Of all the reported driving difficulties, this category of problems was reported to have improved or resolved over time more than any other category.

\section{DISCUSSION}

The goals of this study w ere to document the prevalence and types of driving difficulties in a sample of OIF/ OEF veterans seen at a VA polytrauma outpatient clinic. To our knowledge, no studies have investigated the prevalence or types of driving problems in this cohort to date.

The driving questionnaire indicated that driving problems were common in our sample, with 93 percent of participants self-reporting a negat ive change in at least one 
Table 2.

Qualitative driving problems reported by survey respondents.

\begin{tabular}{|c|c|c|c|}
\hline Driving Problem & Sample Participant Response & $\begin{array}{c}\text { \% Symptoms } \\
\text { Reported as } \\
\text { Persisting (out of } \\
79 \text { reported } \\
\text { symptoms) }\end{array}$ & $\begin{array}{l}\text { \% Symptoms } \\
\text { Reported as } \\
\text { Improved or } \\
\text { Resolved (out of } \\
20 \text { reported } \\
\text { symptoms) }\end{array}$ \\
\hline 1. Anger/Aggression/Impatience & $\begin{array}{l}\text { Has more of a temper than before deployment. } \\
\text { Frustrated more easily; would ram into other vehicles if he } \\
\text { would not get in trouble. }\end{array}$ & $23(n=18)$ & $20(n=4)$ \\
\hline 2. Lapses in Attention/Zoning Out & $\begin{array}{l}\text { Sometimes zones out while driving, thinking about Iraq, and } \\
\text { will drive by where he is going. } \\
\text { Not sure how he reaches destinations because mind wanders. }\end{array}$ & $18(n=14)$ & $5(n=1)$ \\
\hline $\begin{array}{l}\text { 3. Battlemind Training/Misperceived } \\
\text { Threat/Reaction to Benign Stimuli }\end{array}$ & $\begin{array}{l}\text { Tells wife to run through toll booths because he is afraid to stop. } \\
\text { Gets anxious driving under bridges. } \\
\text { Has had many near misses because he is afraid of pedestrians } \\
\text { and does not always stop for crosswalks. }\end{array}$ & $15(n=12)$ & $30(n=6)$ \\
\hline 5. Disorientation/Navigation Problems & Has lots of problems with directions, had to get GPS. & $8(n=6)$ & $5(n=1)$ \\
\hline 6. Anxiety & Has noticed heart racing when driving at night. & $6(n=5)$ & $0(n=0)$ \\
\hline 7. Flashbacks & Still has flashbacks, which cause him to have near misses. & $6(n=5)$ & $0(n=0)$ \\
\hline 8. Avoidance of Driving & $\begin{array}{l}\text { Doesn't drive at all because of PTSD_-it's hard to be in a vehi- } \\
\text { cle at all. }\end{array}$ & $5(n=4)$ & $15(n=3)$ \\
\hline 9. Physical/Sensory Problems & Has most trouble driving at night because of vision issues. & $3(n=2)$ & $0(n=0)$ \\
\hline 10. Miscellaneous & $\begin{array}{l}\text { Thinks a driving course would be helpful if it were available, } \\
\text { because it would help a lot if everyone got retrained in driving. }\end{array}$ & $6(n=5)$ & $20(n=4)$ \\
\hline
\end{tabular}

Table 3.

Persistence or improvement of driving problems reported by clinical groups.

\begin{tabular}{lcc}
\hline \multicolumn{1}{c}{ Group } & $\begin{array}{c}\text { Persisting } \\
(\mathbf{\%})\end{array}$ & $\begin{array}{c}\text { Improved or } \\
\text { Resolved (\%) }\end{array}$ \\
\hline TBI Only (total responses = 12) & 50 & 50 \\
PTSD Only (total responses $=19)$ & 79 & 21 \\
TBI + PTSD (total responses $=59)$ & 88 & 12 \\
Neither (total responses $=9$ ) & 67 & 33 \\
\hline PTSD = postraumatic stess disor
\end{tabular}

PTSD = posttraumatic stress disorder, TBI = traumatic brain injury.

domain of driving ability since returning from deployment. The three most common driving-related problems endorsed by veterans in our samp le were increased anger or impa tience, general driving difficulties, and near misses, respectively. This pattern held true not only for the sample as a whole, but also when the sample was broken down into the four diagnostic groups (TBI only, PTSD only, TBI + PTSD, and Neither). A simi lar pattern emerged in the qualitative data. The mo st frequent driving-related comments were related to increa sed anger, aggression, and impatience; frequent lapses in attention; and difficulties adjusting to driving in a no ncombat (nonthreatening) environment, respectively. As described by some res pondents, lapses in attention could be related to the prev iously described increase in near misses.

Veterans who had returned to a civilian setting sooner would be expected to have quicker diminishment or resolution of postdeployment readjustment problems. Yet, we observed the opposite in our sample. Patients who were diagnosed with PTSD had been back from deployment for significantly longer than patients without PTSD, but more patients with PTSD reported problems with anger and disorientation while driving. Moreover, although the small sample size comprising Table 3 precludes making generalizations, participants in this sample with a diagnosis of 
PTSD (PTSD only or PTSD + TBI) appear to have more persistent driving problems than participants without PTSD. The discrepancy in the resolution of driving dif ficulties might be due to the chronic nature of PTSD symptoms (given the low rate of recovery in untreated patients) [37], unlike the symptoms of mTBI, which are generally expected to resolve without treatment within a month of injury [24]. Our findings are consistent with other studies reporting that PTSD symptoms and deploym ent-related mTBI are ass ociated with self-perceived impairments in emotional, physical, and social functioning [38-39]. Similarly, Sayer et al. found th at OIF/OEF veterans with probable PTSD experience anger (though not necessarily while driving), engage in dangerous driving upon returning home, and generally struggle more with reintegration than veterans without PTSD [40]. Irrespective of the significant group differences, we highlight that selfreported anger/impatience ranged from 65.2 percent (Neither group) to 88.0 percent (TBI $+\mathrm{P}$ TSD group) and becoming lost/disoriented ranged from 21.7 percent (Neither group) to 62.5 percent (PTSD only group), indicating that these emotional and cognitive/perceptual drivingrelated problems were prevalent in this OIF/OEF veteran sample. We caution that we do not know what types of therapies or treatments these veterans may have received since their return from deployment, which might also account for this difference in the remission of driving difficulties between groups.

Overlap of mTBI and PTSD symptoms has been documented [14], and in the current study, we observed a general trend that proportionally more individuals diagnosed with PTSD and coexisting TBI and P TSD tended to endorse the driving-related problems itemized in the driv ing questionnaire. These preliminary results suggest that while all patients undergoing an mTBI evaluation sh ould be queried on driving-related issues, i ncreased attention should be paid to those with a PTSD diagnosis. Indeed, the qualitative responses offered by veterans indicated that PTSD-related symptoms (i.e., exaggerated startle response, hypervigilance, anxiety, anger, difficulties with attention/ concentration, flashbacks, and avoidance of driving) were problematic, and even though some symptoms resolved over time, many still persiste $\mathrm{d}$ years beyond return from deployment. An ext ensive literature exists regarding an association between motor vehicle accidents and the development of PTSD [41-45], yet no studies (to our knowledge) have specifically examined how PTSD affects driving. With an estimated range of 75,000 to 225,000
OIF/OEF servicemembers who will be diagnosed with PTSD and given the types of driving-related problem areas described in the current sample, PTSD's association with driving problems warrants further study, because driving is an important activity of daily living.

Several factors could be contributing to the driving difficulties that veterans descri bed. All soldiers undergo battlemind training that teaches them aggressive driving skills that are meant to be life-preserving in a combat situation. Numerous veterans reported having difficulty unlearning these behaviors once returned to a civilian setting. While this category was noted to be the most likely to improve or resolve following return from deployment, the smal 1 sample size precludes identifying specific factors regarding who will get better.

\section{Role of Sleep Disturbance and Substance Abuse in PTSD and Driving Issues}

As described, cognitive dysfunction (particularly in the areas of attention/concentration and executive functioning), emotional dysregulation, and increased startle response are symptoms of P TSD that may negatively affect driving performance. Although not assessed in the current study, additional cont ributors to decreased driv ing performance could be sleep disruption and substance abuse, which are commonly comorbid with PTSD. A growing body of research suggests that PTSD negatively affects sleep [46-48]. In one study of OIF/OEF veterans who had various combinations of the "Polytrauma Clinical Triad" of pain, PTSD, and TBI, nearly 94 percent of the sample reported trouble falling or staying asleep [49]. Similarly, problematic substance use is e ndorsed by a greater number of OIF/OEF veterans with $\mathrm{P}$ TSD compared with those without PTSD [40,50]. Given that insufficient sleep is known to impair driving ability [51-54] and problematic drinking has been linked to even greater risk for collisions [55], it seems likely that both problems could also be contributing to the driving difficulties noted in our sample. Alth ough patients in the presen t study were not systematically evaluated for any type of sleep problems or substance abuse, future studies are needed to examine the impact of these conditions on driving safety in individuals with PTSD.

\section{Limitations}

A number of limitations to the study should be addressed. Participants were recruited from a single VA polytrauma outpatient clinic that, by its nature, evaluates 
and treats veterans who have sustained physical, cognitive, or emotional injuries. Therefore, the ra tes of TBI and PTSD in our sample are likely higher than in the general OIF/OEF veteran population. Also important to note is that only 205 out of 450 people were able to be reached and agreed to participate in the study. Contacting those who were not working or were prone to staying at home may have been easier, and therefore, this may represent a biased sample with higher rates of TBI and/or PTSD, diagnoses that may limit function and participation in the workforce. Although slightly less than half responded to the survey, we note that the study's 45.6 percent participation rate is in the response rate range $(28.5 \%$ to $59.0 \%)$ [31,56-57] of other published OIF/OEF servicemember survey responses.

Cognitive deficits associated with TBI may lead to memory difficulty and inability to accurately identify problems one may have experienced. In th is study, respondents recalled driving behaviors, on average, 3.5 to 4.0 years after return from deployment and the driving questionnaire also did not define a circumscribed period upon return (e.g., 3 months) to consider driving difficulties. Together this may have led to an underreporting of symptoms, recall bias, or other memory inac curacies. Future studies should be designed to prospectively follow veterans longitudinally and assess driving problems veterans encounter immediately upon return from deployment as well as over time. These studies may also want to include observations from significant others to corroborate self-reported findings. This systematic approach would allow for tar geted assessment and rehabilitation strategies for safe driving.

The primary instrument used to gather the data col lected in this study also has some limitations. The driving questionnaire was created specifically for this study and its psychometric properties have yet to be evaluated. Although the wording of the questions may also have elicited a response bias towa rd reporting an increase in driving difficulties, all questions were worded the same way and therefore had an equal likelihood of eliciting an "increased" report of driving problems. While the data may represent an overendorsement of driving difficulties, the pattern of responses among the questions may reflect a pattern that is represent ative of the specific problems that OIF/OEF veterans with P TSD and TBI are experi encing. We also note that the driving-related problems sampled in the questionnaire may not be independent from one another and that some may be manifestations of others (e.g., near misses resulting from lapses in attention), as suggested by respondent comments. However, we believe that this study provides a snapshot of drivingrelated problems that some veterans are currently experiencing and provides a good foundation for further exploration of OIF/OEF veteran driving issues.

Another limitation of the study is that the qualitative data were not gathe red in a structured manne $r$, because those who mailed back their surveys were not given an explicit opportunity to offer comment. By contrast, comments from telephone respondents were elicited and recorded by the interviewers when respondents offered thoughts beyond their responses to the driving quest ionnaire. The qual itative data reported here may not fully capture in detail the extent to which all veterans from our sample were having driving-related issues.

Considering the existing literature documenting the negative impacts of moderate to severe TBI on driving skills [58], we emphasize that the findings in this present study should not be generalized to other TBI populations, which include a spectrum of mild, moderate, and severe TBIs. Instead, the current findings are likely specific to patients seen in a VA PNS outpatient clinic.

\section{Implications}

While definitive conclusions cannot be drawn from the data collected in this study, the data suggest that postdeployment driving dif ficulties are a real problem that many veterans in our sample experienced. Furthermore, a relationship between driving $\mathrm{d}$ ifficulties and P TSD appears to exist. Given the large number of veterans who have, or will have, served in the current war, the consequences of unsafe driving have the potential to be significant and widespread. It is critical that appropriate prevention, assessment, and treatment programs be established to a ddress driving-related issues. For e xample, many participants in our sample anecdotally noted that their driving difficulties were most noticeable during the first several months after returning home. Just as soldiers are taught combat driving skills before deployment, they may need to be retaught civi lian driving skills and safe driving practices upon their return. Increased anger and impatience while driving were significant concerns for the majority of the participants in our sample, even those without a history of PTSD or TBI. Instruction in angermanagement strategies to be u sed when driving may be beneficial to returning OIF/OEF servicemembers. This is an issue that must continue to be addressed and studied in 
order to provide veterans $\mathrm{w}$ ith the skills they need to ensure a smooth and safe transition when returning home from deployment.

\section{CONCLUSIONS}

In this study, $205 \mathrm{OIF} / \mathrm{OEF}$ veterans completed a survey comparing their current civilian driving ability to predeployment driving skills and 93 percent reported experiencing some degree of increased driving difficulty. Comments offered by respondents suggested that difficulties with anger, unlearning battlemind driving behaviors, and sustaining attention while driving were the most common types of problems experienced in this sample of OIF/OEF veterans. While the limited sample precludes large-scale generalizability, these findings suggest a sig nificant and serious problem that has potentially fatal consequences for both veterans and other drivers on the road. Given the large number of people potentially affected by this issue, ad ditional research to devel op ways of addressing the driving-related difficulties experienced by OIF/OEF veterans is imperative.

\section{ACKNOWLEDGMENTS}

\author{
Author Contributions: \\ Obtained funding: H. L. Lew. \\ Study concept and design: H. L. Lew, M. Kraft, P. Woods. \\ Data collection: M. Kraft, M. M. Amick, P. Woods. \\ Analysis and interpretation of data: H. L. Lew, M. Kraft, T. K. Pogoda, \\ M. M. Amick, P. Woods. \\ Statistical expertise: T. K. Pogoda, M. M. Amick. \\ Drafting of manuscript: H. L. Lew, M. Kraft, T. K. Pogoda, D. X. Cifu \\ (original contributions to "Introduction" and "Discussion"). \\ Critical revision of manuscript for important intellectual content: H. L. \\ Lew, T. K. Pogoda, M. M. Amick, D. X. Cifu. \\ Final approval of authorship: M. M. Amick, M. Kraft, H. L. Lew, T. K. \\ Pogoda. \\ Study supervision: H. L. Lew. \\ Financial Disclosures: The authors have declared that no competing \\ interests exist.
}

Funding/Support: This material was based on work supported by VA Merit Review Grant B5009R.

Additional Contributions: Dr. Lew is now affiliated with the University of Hawaii at Manoa, John A. Burns School of Medicine, Honolulu, Hawaii; and the Defense and Veterans Brain Injury Center, Richmond, Virginia.

Institutional Review: All study procedures and data collection instruments were approved by the local VA Institutional Review Board.
Participant Follow-Up: The authors do not plan to inform participants of the publication of this study.

\section{REFERENCES}

1. Department of Defense Injury Surveillance and Prevention Work Group for the Assistant Deputy Under Secretary of Defense for Safety and Occupational Health. Atlas of injuries in the United States Armed Forces. Mil Med. 1999; 164(8 Suppl):633 pages. [PMID: 10570846]

2. Veterans' safe driving initiative [Internet]. Washington (DC): Department of Veterans Affairs; 2010 [updated 2010 Dec 29; cited 2009 Nov 25]. Available from:

http://www.safedriving.va.gov/.

3. Carden MJ. Deptartments launch safe-driving initiative for veterans [Internet]. Washington (DC): Department of Defense [cited 2011 Jun 29]. Available from: http://www.defense.gov/news/newsarticle.aspx?id=52651

4. Lincoln AE, Hooper TI, Kang HK, Debakey SF, Cowan DN, Gackstetter GD. Motor vehicle fatalities among Gulf War era veterans: Characteristics, mechanisms, and circumstances. Traffic Inj Prev. 2006;7(1):31-37. [PMID: 16484030] DOI:10.1080/15389580500412028

5. Boehmer TK, Flanders WD, McGeehin MA, Boyle C, Barrett DH. Postservice mortality in Vietnam veterans: 30-year follow-up. Arch Intern Med. 2004;164(17):1908-16.

[PMID: 15451767] DOI:10.1001/archinte.164.17.1908

6. Knapik JJ, Marin RE, Grier TL, Jones BH. A systematic review of post-deployment injury-related mortality among military personnel deployed to conflict zones. BMC Public Health. 2009;9:231. [PMID: 19594931] DOI:10.1186/1471-2458-9-231

7. Sivak M. Motor-vehicle safety in Europe and the USA: A public-health perspective. J Safe Res. 1996;27(4):225-31.

8. Lew HL, Amick MM, Kraft M, Stein MB, Cifu DX. Potential driving issues in combat returnees. NeuroRehabilitation. 2010;26(3):271-78. [PMID: 20448316]

9. Fear NT, Iversen AC, Chatterjee A, Jones M, Greenb erg N, Hull L, Rona RJ, Hotopf M, Wessely S. Risky driving among regular armed forces personnel from the United Ki ngdom. Am J Prev Med. 2008;35(3):230-36. [PMID: 18617356] DOI:10.1016/j.amepre.2008.05.027

10. Hooper TI, DeBakey SF, Lincoln A, Kang HK, Cowan DN, Gackstetter GD. Leveraging existing databases to study vehicle crashes in a combat occupational cohort: Epidemiologic methods. Am J Ind Med. 2005;48(2):118-27.

[PMID: 16032740] DOI:10.1002/ajim.20190

11. Kang HK, Bullman TA, Macfarlane GJ, Gray GC. Mortality among US and UK veterans of the Persian Gulf War: A 
review. Occup Environ Med. 2002;59(12):794-99.

[PMID: 12468744$]$

DOI:10.1136/oem.59.12.794

12. Castro CA, Hoge CW. Building psychological resiliency and mitigating the risks of combat and deployment stressors faced by soldiers. Proceedings of the NATO Research and Technology Organisation Human Factors and Medical Panel (RTOMP-HFM-124); 2005 Oct 3-5; Prague, Czech Republic. Neuilly-sur-Seine Cedex (France): Research and Technology Organisation.

13. Walter Reed Army Institut e of $R$ esearch. Continuing the transition home: Battlemind. Proceedings of the Combat Stress Related Disorder Conference, 2007; VA Montana Healthcare System. Available from: http://www.triwest.com/ unauth/content/provider/LocalProviderNews/MT/battlemind.pdf

14. Lew HL, Vanderploeg RD, Moore DF, Schwab K, Friedman L, Yesavage J, Keane TM, Warden DL, Sigford BJ. Overlap of mild TBI and ment al health conditions in returning OIF/ OEF service members and veterans. J Rehab il Res Dev. 2008;45(3):xi-xvi. [PMID: 18629743]

15. Kang HK, Natelson BH, Mahan CM, Lee KY, Murphy FM. Post-traumatic stress disorder and chronic fatigue syndrome-like illness among Gulf War veterans: A populationbased survey of 30,000 veterans. Am J Epidemiol. 2003; 157(2):141-48. [PMID: 12522021]

DOI:10.1093/aje/kwf187

16. Dohrenwend BP, Turner JB, Turse NA, Adams BG , Koenen $\mathrm{KC}$, Marshall R. The psychological risks of Vietnam for U.S. veterans: A revisit with new data and methods. Science. 2006;313(5789):979-82. [PMID: 16917066] DOI:10.1126/science. 1128944

17. Tanielian T, Jaycox LH, editors. Invisible wounds of war: Psychological and cognitive injuries, their consequences, and services to assist recovery [Internet]. Santa Monica (CA): RAND Corporation; 2008 [updated 2011 Feb 11; cited 2009 Jul 17]. Available from: http://www.rand.org/ pubs/monographs/MG720.

18. Hoge CW, Castro CA, Messer SC, McGurk D, Cotting DI, Koffman RL. Combat duty in Iraq and Afghanistan, mental health problems, and barriers to care. N Engl J Med. 2004; 351(1):13-22. [PMID: 15229303]

DOI:10.1056/NEJMoa040603

19. Vasterling JJ, Proctor SP, Amoroso P, Kane R, Heeren T, White RF. Neuropsychological outcomes of army personnel following deployment to the Iraq war. JAMA. 2006; 296(5):519-29. [PMID: 16882958]

DOI:10.1001/jama.296.5.519

20. Hoge CW, Terhakopian A, Castro CA, Messer SC, Engel CC. Association of $\mathrm{p}$ osttraumatic stress disorder with somatic symptoms, health care vis its, and absenteeism among Iraq war veterans. Am J Psychiatry. 2007;164(1):150-53.
[PMID: 17202557]

DOI:10.1176/appi.ajp.164.1.150

21. Atkinson MP, Guetz A, Wein LM. A dynamic model for posttraumatic stress disorder among U.S. troops in Operation Iraqi Freedom. Manage Sci. 2009;55(9):1454-68. DOI:10.1287/mnsc.1090.1042

22. Korb LJ, Rundlet P, Bergmann M, Duggan S, Juul P. Beyond the call of duty: A comprehensive review of the overuse of the Army in the administration's war of choice in Iraq [Int ernet]. Washington (DC): Center for Ame rican Progress; 2007 [cited 2009 Dec 4]. Available from: http://www.americanprogress.org/issues/2007/03/ readiness report.html.

23. Reger MA, Gahm GA, Swanson RD, Duma SJ. Association between number of deployments to Iraq and mental health screening outcomes in US Army soldiers. J Clin Psychiatry. 2009;70(9):1266-72. [PMID: 19689917]

DOI:10.4088/JCP.08m04361

24. McAllister TW. Neurobehavioral sequelae of traumatic brain injury: Evaluation and management. World Psychiatry. 2008;7(1):3-10. [PMID: 18458777]

25. Marx BP, Doron-Lamarca S, Proctor SP, Vasterling JJ. The influence of pre-deployment neurocognitive functioning on post-deployment PTSD symptom outcomes among Iraqdeployed Army soldiers. J Int Neuropsychol Soc. 20 09; 15(6):840-52. [PMID: 19891817] DOI: $10.1017 / \mathrm{S} 1355617709990488$

26. Leskin LP, White PM. Attentional networks reveal executive function deficits in posttraumatic stress disorder. Neuropsychology. 2007;21(3):275-84. [PMID: 17484590] DOI:10.1037/0894-4105.21.3.275

27. Samuelson KW, Neylan TC, Metzler TJ, Lenoci M, Rothlind J, Henn-Haase C, Choucroun G, Weiner MW, Marmar CR. Neuropsychological functioning in posttraumatic stress disorder and alcohol abuse. Neuropsychology. 2006;20(6): 716-26. [PMID: 17100516] DOI:10.1037/0894-4105.20.6.716

28. Wickens CM, Toplak ME, Wiesenthal DL. Cognitive failures as predictors of driving errors, lapses, and violations. Accid Anal Prev. 2008;40(3):1223-33. [PMID: 18460392] DOI:10.1016/j.aap.2008.01.006

29. Warden D. Military TBI during the Iraq and Afghanistan wars. J Head Trauma Rehabil. 2006;21(5):398-402. [PMID: 16983225] DOI:10.1097/00001199-200609000-00004

30. Schwab KA, Warden D, Lux WE, Shupenko LA, Zitnay G. Defense and veterans brain injury cente $r$ : Peacetime and wartime missions. J Rehabil Res Dev. 2007;44(7):xiii-xxi. [PMID: 18075946]

31. Hoge CW, McGurk D, Thom as JL, Cox A L, Engel CC, Castro CA. Mild traumatic brain i njury in U.S. Sol diers returning from Iraq. N Engl J Med. 2008;358(5):453-63. 
JRRD, Volume 48, Number 8, 2011

[PMID: 18234750]

DOI:10.1056/NEJMoa072972

32. Ryan LM, Warden DL. Post concussion syndrome. Int Rev Psychiatry. 2003;15(4):310-16. [PMID: 15276952]

DOI:10.1080/09540260310001606692

33. Schneiderman AI, Braver ER, Kang HK. Und erstanding sequelae of injury mechanisms and mild traumatic brain injury incurred during the conflicts in Iraq and Afghanistan: Persistent postconcussive symptoms and posttraumatic stress disorder. Am J Epid emiol. 2008;167(12): 1446-52. [PMID: 18424429]

DOI:10.1093/aje/kwn068

34. Vanderploeg RD, Belanger HG, Curtiss G. Mild traumatic brain injury and posttraumatic stress disorder and their associations with health symptoms. Arch Phys Med Rehabil. 2009;90(7):1084-93. [PMID: 19577020] DOI:10.1016/j.apmr.2009.01.023

35. Kay T, Harrington DE, Adams R, Anderson T, Berrol S, Cicerone K, Dahlberg C, Gerber D, Goka R, Harley P, Hilt J, Horn L, Lehmkuhl D, Malec J. Definition of mild traumatic brain injury. J Head Trauma Rehabil. 1993;8(3):86-87. DOI:10.1097/00001199-199309000-00010

36. Management of Concussion/mTBI Working Group. VA/ DoD clinical practice guideline for management of concussion/mild traumatic brain injury [Internet]. Washington (DC): VA/DoD Evidence Based Practice; 2009 [cited 2011 Jun 23]. Available from: http://www.healthquality.va.gov/ mtbi/concussion mtbi full 1_ 0.pdf

37. Schnurr PP, Friedman MJ, Engel CC, Fo a EB, Shea MT, Chow BK, Resick PA, Thurston V, Orsillo SM, Haug R, Turner C, Bernardy N. Cognitive behavioral therapy for posttraumatic stress disorder in women: A randomized controlled trial. JAMA. 2007;297(8):820-30. [PMID: 17327524]

DOI:10.1001/jama.297.8.820

38. Lippa SM, Pastorek NJ, Benge JF, Thornton GM. Postconcussive symptoms after blast and nonblast-related mild traumatic brain injuries in Afghanistan and Iraq war veterans. J Int Neuropsychol Soc. 2010;16(5):856-66.

[PMID: 20682086]

DOI:10.1017/S1355617710000743

39. Polusny MA, Kehle SM, Nelson NW, Erbes CR, Arbisi PA, Thuras P. Longitudinal effects of mild traumatic brain injury and posttraumatic stress disorder comorbidity on postdeployment outcomes in national guard soldiers deployed to Iraq. Arch Gen Psychiatry. 2011;68(1):79-89. [PMID: 21199967] DOI:10.1001/archgenpsychiatry.2010.172

40. Sayer NA, Noorbaloochi S, Frazier P, Carlson K, Gravely A, Murdoch M. R eintegration problems and treatment interests among Iraq and Afghani stan combat veterans receiving VA medical care. Ps ychiatr Serv. 2010;61(6): 589-97. [PMID: 20513682]

DOI:10.1176/appi.ps.61.6.589
41. Kuch K, Cox BJ, Evans RJ. Posttraumatic stress disorder and motor vehicle accidents: A multidisciplinary overview. Can J Psychiatry. 1996;41(7):429-34. [PMID: 8884031]

42. Kupchik M, Strous RD, Erez R, Gonen N, Weizman A, Spivak B. D emographic and cli nical characteristics of motor vehicle accident victims in the community general health outpatient clinic: A comparison of PTSD and non-PTSD subjects. Depress Anxiety. 2007;24(4):244-50.

[PMID: 17001628]

DOI:10.1002/da.20189

43. Matsuoka Y, Nishi D, Nakajima S, Kim Y, Homma M, Otomo Y. Incidence and prediction of psychiatric morbidity after a motor vehicle accident in Japan: The Tachikawa Cohort of Motor Vehicle Accident Study. Crit Care Med. 2008;36(1):74-80. [PMID: 18090377] DOI:10.1097/01.CCM.0000291650.70816.D6

44. Mayou RA, Ehlers A, Bryant B. Posttraumatic stress disorder after motor vehicle accidents: 3-year follow-up of a prospective longitudinal study. Behav Res Ther. 2002;40(6): 665-75. [PMID: 12051485] DOI:10.1016/S0005-7967(01)00069-9

45. Ursano RJ, Fullerton CS, Epstein RS, Crowley B, Kao TC, Vance K, Craig KJ, Dougall AL, Baum A. Acu te and chronic posttraumatic stress disorder in motor vehicle accident victims. Am J Psychiatry. 1999;156(4):589-95. [PMID: 10200739]

46. Maher MJ, Rego SA, Asnis GM. Sleep d isturbances in patients with post-traumatic stress disorder: Epidemiology, impact and approaches to management. CNS Drugs. 2006; 20(7):567-90. [PMID: 16800716] DOI:10.2165/00023210-200620070-00003

47. Lewis V, Creamer M, Failla S. Is poor sleep in veterans a function of post-traumatic stress disorder? Mil Med. 2009; 174(9):948-51. [PMID: 19780370]

48. Calhoun PS, Wiley M, Dennis MF, Means MK, Edi nger JD, Beckham JC. Objective evid ence of sleep disturbance in women with posttraumatic stress disorder. J T rauma Stress. 2007;20(6):1009-18. [PMID: 18157880] DOI:10.1002/jts.20255

49. Lew HL, Pogoda TK, Hsu PT, Cohen S, Amick MM, Baker E, Meterko M, Vanderploeg RD. Impact of the "polytrauma clinic triad" on sleep disturbance in a Department of Veterans Affairs outpatient rehabilitation setting. Am J Phys Med Rehabil. 2010;89(6):437-45. [PMID: 20489391] DOI:10.1097/PHM.0b013e3181ddd301

50. Thomas JL, Wilk JE, Riviere LA, McGurk D, Castro CA, Hoge CW. Prevalence of mental health problem s and functional impairment among active component and National Guard soldiers 3 and 12 months following co mbat in Iraq. Arch Gen Psychiatry. 2010;67(6):614-23. [PMID: 20530011] DOI:10.1001/archgenpsychiatry.2010.54 
51. Miyata S, Noda A, Ozaki N, Hara Y, Minoshima M, Iwamoto K, Takahashi M, Iidaka T, Koike Y. Insufficient sleep impairs driving performance and cognitive function. Neurosci Lett. 2010;469(2):229-33. [PMID: 19969042] DOI:10.1016/j.neulet.2009.12.001

52. Contardi S, Pizza F, Sancisi E, Mondini S, Cirignotta F. Reliability of a driv ing simulation task for evaluation of sleepiness. Brain Res Bull. 2004;63(5):427-31. [PMID: 15245771] DOI:10.1016/j.brainresbull.2003.12.016

53. Philip P, Sagaspe P, Taillard J, Valtat C, Moore N, Akerstedt T, Charles A, Bioulac B. Fatigue, sleepiness, and performance in simulated versus real driving conditions. Sleep. 2005; 28(12):1511-16. [PMID: 16408409]

54. Ware JC, Risser MR, Manser T, Karlson KH Jr. Medical resident driving simulator performance following a night on call. Behav Sleep Med. 2006;4(1):1-12. [PMID: 16390281] DOI:10.1207/s15402010bsm0401 1

55. Mann RE, S toduto G, Vingilis E, Asbridg e M, W ickens CM, Ialomiteanu A, Sharpley J, Smart RG. Alcohol and driving factors in collision risk. Accid Anal Prev. 2010; 42(6):1538-44. [PMID: 20728600] DOI:10.1016/j.aap.2010.03.010

56. Amin MM, Parisi JA, Gold MS, Gold AR. War-related illness symptoms among Operation Iraqi Freedom/Operation Enduring Freedom returnees. Mil Med. 2010;175(3):155-57. [PMID: 20358703]

57. Pietrzak RH, Johnson DC, Goldstein MB, Malley JC, Rivers AJ, Morgan CA, Southwick SM. Psychosocial buffers of traumatic stress, depressive symptoms, and psychosocial difficulties in veterans of Operations Enduring Freedom and Iraqi Freedom: The role of resilience, unit support, and postdeployment social support. J Spec Oper Med. 2009; 9(3):74-78. [PMID: 19739480]

58. Lew HL, Poole JH, Lee EH, Jaf fe DL, Huang HC, Brodd E. Predictive validity of driving-simulator assessments following traumatic brain injury: A preliminary study. Brain Inj. 2005;19(3):177-88. [PMID: 15832892]

DOI:10.1080/02699050400017171

Submitted for publication August 2, 2010. Accepted in revised form February 16, 2011.

This article and any supplementary material should be cited as follows:

Lew HL, Kraft M, Po goda TK, Amick MM, Woods P, Cifu DX. Prevalence and characteristics of driving difficulties in Operation Iraqi Freedom/Operation Enduring Freedom combat returnee s. J Rehabil Res Dev. 2011; 48(8):913-26.

DOI:10.1682/JRRD.2010.08.0140

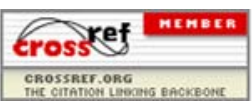


